\title{
IMPACT OF FAMILY STIGMA AND CAREGIVER BURDEN ON QUALITY OF LIFE AMONG WIVES OF PATIENTS WITH ALCOHOL AND OPIOID USE DISORDER
}

\author{
ROHIT GARG ${ }^{*}$, ABHISHEK GUPTA ${ }^{2}$, DEEPAM KUNDAL ${ }^{1}$, SAVIJOT SINGH $^{3}$
}

${ }^{1}$ Department of Psychiatry, Government Medical College, Patiala, Punjab, India. ${ }^{2}$ Department of Psychiatry, All India Institute of Medical Sciences, New Delhi, India. ${ }^{3}$ Department of Surgery, Government Medical College, Patiala, Punjab, India. Email: drrohitgarg@hotmail.com

Received: 28 August 2021, Revised and Accepted: 09 October 2021

\section{ABSTRACT}

Objectives: Spouses of patients with alcohol use disorder (AUD) and opioid use disorder (OUD) suffer from burden, stigma, and low quality of life (QoL). The present study assessed the impact of stigma and burden on QoL among wives of patients with AUD and OUD.

Methods: 90 wives of in-patients with severe AUD ( $n=54)$ and OUD ( $n=36)$ as per DSM-5 were assessed using socio-demographic pro forma, WHO QoL Bref Hindi, Hindi family stigma scale and Family Burden Interview Schedule. Statistical Package for the Social Sciences Inc., Chicago, IL, version 25.0 for Windows was used for analysis. Appropriate statistical tests including Kolmogorov-Smirnov tests of normality, Mann-Whitney test, and Kruskal-Wallis test were used. To see the relationship between two variables Pearson Correlation coefficient was calculated. All statistical tests were two-sided and performed at a significance level of $\alpha=.05$.

Results: Majority of the wives were more than 30 years old, literate and belonged to rural areas. Higher financial burden reduced overall QoL $\left(\mathrm{p}=0.001^{* *}\right)$, satisfaction with physical health $\left(0.006^{* *}\right)$, psychological health $\left(\mathrm{p}=0.032^{*}\right)$, and environment $\left(\mathrm{p}=0.001^{* *}\right)$. There was a negative correlation of satisfaction with environment with disruption of family interaction $\left(\mathrm{p}=0.003^{* *}\right)$, burden on mental health $\left(\mathrm{p}=0.001^{* *}\right)$, overall burden $\left(\mathrm{p}=0.000^{* *}\right)$, and discrimination $\left(\mathrm{p}=0.032^{*}\right)$.

Conclusion: QoL of spouses of patients with AUD and OUD reduces significantly due to stigma and burden. Enhancing QoL of spouses should be a part of management of AUD and OUD.

Keywords: Alcohol, Burden, Opioid, Quality of life, Stigma, Wives.

(C) 2021 The Authors. Published by Innovare Academic Sciences Pvt Ltd. This is an open access article under the CC BY license (http://creativecommons.org/ licenses/by/4.0// DOI: http://dx.doi.org/10.22159/ajpcr.2021v14i11.43006. Journal homepage: https://innovareacademics.in/journals/index.php/ajpcr

\section{INTRODUCTION}

Substance use disorders (SUD) cause significant burden and stigma to patients as well as their family members. It leads to a significant reduction in quality of life (QoL) of patients and their spouses [1]. Caregiver burden is the strain or load borne by a person caring for an elderly, chronically ill or disabled family member [2]. Multiple studies have demonstrated very high caregiver burden among spouses of patients with SUD [3]. The burden could be financial, psychological, physical, disruption in family routine, interaction, leisure activities, etc. [3]. Wives of persons with SUD face stigma and discrimination which causes avoidance, reduced life opportunities, guilt, social exclusion, reduced self-esteem, hopelessness, treatment gap, poor compliance, etc. [4]. To the best of our knowledge of the authors, no study from India has assessed the impact of caregiver burden and family stigma on QoL. Studies from elsewhere have reported that family stigma reduced QoL, anticipated stigma had direct negative impact on psychological and physical health, and caregiver burden significantly reduces QoL of spouses of patients with SUD [5-7]. The present study was planned to assess the impact of burden and family stigma on QoL among spouses of patients with SUD.

\section{METHODS}

It was a descriptive, cross-sectional study conducted from January to October 2019 at the 50 bedded Model De-addiction Centre of Department of Psychiatry, Government Medical College and Hospital in North India. 90 wives between 18 and 65 years, who were the primary caregivers and gave written informed consent, were included. The wives of only those patients were included who fulfilled criteria for severe dependence and required admission. Wives who were suffering from SUD and psychiatric illness (as assessed clinically using DSM-5 criteria) were excluded from the study. Wives were excluded if they or their patient suffered from any other medical or surgical disorder which would lead to a reduction in QoL or is stigmatizing such as HIV, hepatitis, leprosy, tuberculosis, and physical handicap. Wives of patients with dual diagnosis or multiple SUD except nicotine and caffeine were also excluded from the study. Wives who refused to participate in the study or whose husband's prohibited them from doing so were excluded. Those who agreed were then assessed using the following tools.

\section{Socio-demographic and clinical pro forma}

A semi-structured pro forma was prepared to record the sociodemographic and clinical variables.

\section{WHO QoL Bref Hindi version}

WHO QoL Bref Hindi version was used to measure subjective health related QoL. The 26 items are further divided into four domains (satisfaction with physical health, psychological health, social relations, and environment) and two general questions related to satisfaction with overall QoL and overall health. This is one of the most commonly used scales to measure QoL and has excellent reliability and validity [8].

\section{Stigma scale}

The Hindi self-stigma scale previously standardized in India was used for the study. It has 28 self-rated items with each item rated from 0 to 2 (agree, neither agree nor disagree and disagree). The 28 items are divided into three domains namely discrimination (13 items), disclosure (ten items), and positive aspects of stigma (five items). Higher score on each domain and the total scale score denotes higher stigma. The scale has been previously standardized in India on a variety of patients with mental illnesses and was found to have good internal consistency and test-retest reliability [9]. 
Family burden interview schedule

It has been developed in India and consists of 24 items grouped into six areas, namely, financial burden, disruption of family activities, family leisure, family interaction, and effect on physical and mental health of others. This is a semi-structured interview schedule with each item rated on a $0-2$ scale. The total score could range from 0 to 48 and the scale has good reliability and validity in India [10].

\section{Ethical considerations}

The study was approved by the institutional ethics committee. Written informed consent was obtained from the wives and assent was obtained from the patients. The Indian Council of Medical Research ethical guidelines on biomedical research on human participants were adhered to.

\section{Statistical analysis}

(Statistical Package for the Social Sciences Inc., Chicago, IL, version 25.0 for Windows) was used for analysis. Quantitative variables were estimated with measures of central location and dispersion. Kolmogorov-Smirnov tests of normality were used to check normality of data. For skewed data, Mann-Whitney test was applied for two groups and Kruskal-Wallis test for more than two groups. Proportions were compared using Chi-square or Fisher's exact test which ever was applicable. To see the relationship between two variables Pearson Correlation coefficient was calculated. All statistical tests were two-sided and performed at a significance level of $\alpha=0.05$.

\section{RESULTS}

The sociodemographic data of the sample and its distribution according to QoL are shown in Table 1 . Out of 90 wives, $63(70 \%)$ were more than $30 y r s$ old and literate but only 21 (23\%) were working. Approximately $60 \%$ belonged to rural areas, living in nuclear family and were wives of patients with alcohol use disorder (AUD). Only $53 \%$ of the families had monthly income more than 10,000 and 53\% of the wives had their husbands admitted in the past for treatment. The mean duration of SUD was $145.60 \pm 104.92$ (range 16-444) months.

The distribution of sociodemographic profile with QoL showed that housewives had significantly better satisfaction with psychological health $\left(\mathrm{p}=0.016^{*}\right)$ on WHO QoL Bref as compared to working women. Other sociodemographic variables were not found to be significant.

There was a significant negative correlation between discrimination and Satisfaction with environment ( $\mathrm{p}=0.032^{*}$ ) as shown in Table 2 .

Financial burden was significantly negatively correlated with overall QoL $\left(\mathrm{p}=0.001^{* *}\right)$, satisfaction with physical health $\left(0.006^{* *}\right)$, with psychological health $\left(\mathrm{p}=0.032^{*}\right)$, and with environment $\left(\mathrm{p}=0.001^{* *}\right)$ as shown in Table 3. Satisfaction with physical health was significantly negatively correlated with disruption in family activities $\left(\mathrm{p}=0.051^{*}\right)$. Satisfaction with environment was significantly negatively correlated with disruption of family interaction $\left(p=0.003^{* *}\right)$, effect on mental health $\left(\mathrm{p}=0.001^{* *}\right)$, and overall burden of care $\left(\mathrm{p}=0.000^{* *}\right)$.

\section{DISCUSSION}

To the best of our knowledge, this is the first Indian effort to study the impact of family-stigma and burden on QoL of wives of patients with SUD. The scores on WHO QoL Bref were in the range of 50-60 in the first three domains (satisfaction with physical health, psychological health, and social relations) and nearly 40 in domain four (satisfaction with environment). The scores in our study are comparable to a previous study among family members of patients with heroin dependence which found that QoL as measured using WHO QoL Bref was between 50 and 60 on all domains and were much lesser than family members of the control group [7]. Although we did not take any control group in the present study, the scores in the present study were much lower than the healthy general population in a previous study [11]. Some other studies from India and elsewhere have also found that the QoL among

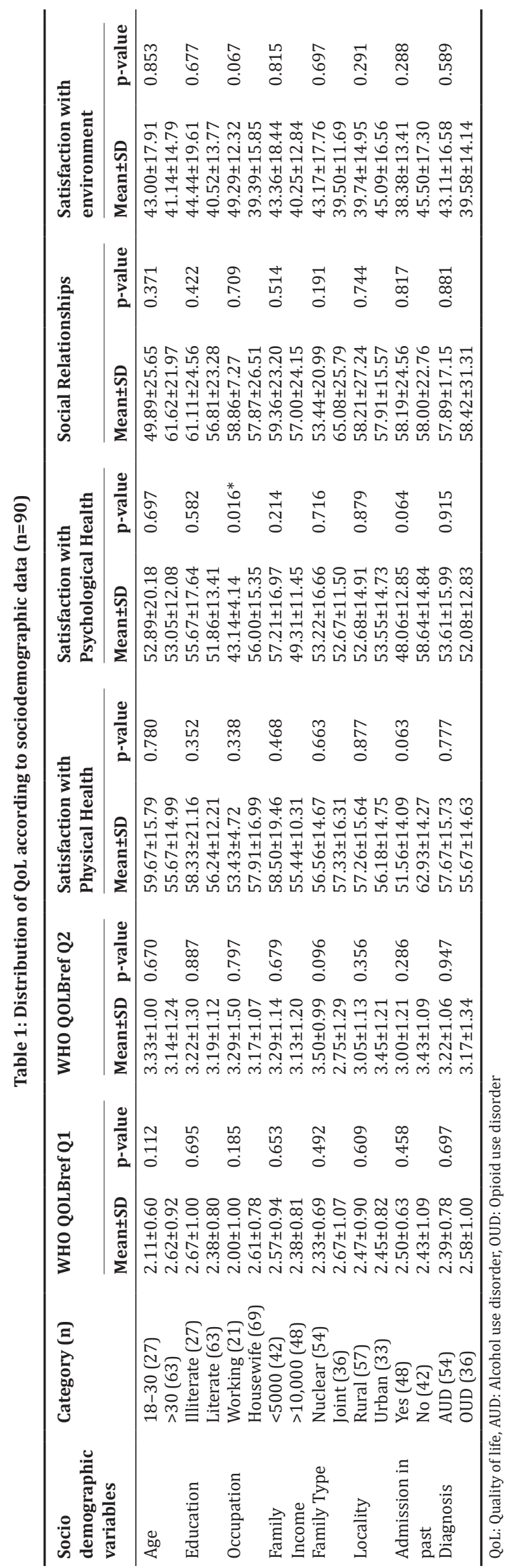


Table 2: Correlation of QoL with Stigma (Pearson Correlations)

\begin{tabular}{|c|c|c|c|c|}
\hline WHO QoL Bref & Discrimination Total & Disclosure Total & Positive Aspects Total & Total Stigma Scale \\
\hline \multicolumn{5}{|l|}{ WHO Qol Bref Q1 } \\
\hline Pearson Correlation & -0.024 & -0.077 & -0.082 & -0.076 \\
\hline p-value & 0.899 & 0.685 & 0.665 & 0.689 \\
\hline \multicolumn{5}{|l|}{ WHO Qol Bref Q2 } \\
\hline Pearson Correlation & 0.061 & 0.167 & 0.157 & 0.165 \\
\hline $\mathrm{p}$-value & 0.748 & 0.379 & 0.408 & 0.385 \\
\hline \multicolumn{5}{|c|}{ Satisfaction with Physical health } \\
\hline Pearson Correlation & -0.117 & -0.219 & -0.028 & -0.200 \\
\hline $\mathrm{p}$-value & 0.538 & 0.245 & 0.883 & 0.289 \\
\hline \multicolumn{5}{|c|}{ Satisfaction with Psychological health } \\
\hline Pearson Correlation & -0.155 & -0.067 & 0.121 & -0.095 \\
\hline $\mathrm{p}$-value & 0.412 & 0.726 & 0.525 & 0.616 \\
\hline \multicolumn{5}{|l|}{ Social relationships } \\
\hline Pearson Correlation & 0.148 & 0.020 & 0.036 & 0.093 \\
\hline $\mathrm{p}$-value & 0.435 & 0.916 & 0.852 & 0.626 \\
\hline \multicolumn{5}{|c|}{ Satisfaction with environment } \\
\hline Pearson Correlation & $-0.392^{*}$ & -0.124 & -0.144 & -0.299 \\
\hline p-value & $0.032^{*}$ & 0.515 & 0.447 & 0.108 \\
\hline
\end{tabular}

QoL: Quality of life

Table 3: Correlation of QoL with Burden (Pearson Correlation)

\begin{tabular}{|c|c|c|c|c|c|c|c|}
\hline WHO QoL Bref & $\begin{array}{l}\text { Financial } \\
\text { Burden }\end{array}$ & $\begin{array}{l}\text { Disruption } \\
\text { of family } \\
\text { activities }\end{array}$ & $\begin{array}{l}\text { Disruption } \\
\text { of family } \\
\text { leisure }\end{array}$ & $\begin{array}{l}\text { Disruption } \\
\text { of family } \\
\text { interaction }\end{array}$ & $\begin{array}{l}\text { Burden on } \\
\text { physical } \\
\text { health }\end{array}$ & $\begin{array}{l}\text { Burden } \\
\text { on mental } \\
\text { health }\end{array}$ & $\begin{array}{l}\text { Overall } \\
\text { Burden }\end{array}$ \\
\hline \multicolumn{8}{|l|}{ WHO QolBref Q1 } \\
\hline Pearson Correlation & $-0.561^{* *}$ & -0.108 & -0.144 & -0.187 & 0.150 & -0.082 & -0.234 \\
\hline p-value & $0.001^{* *}$ & 0.572 & 0.448 & 0.323 & 0.429 & 0.666 & 0.212 \\
\hline \multicolumn{8}{|l|}{ WHO QolBref Q2 } \\
\hline Pearson Correlation & -0.292 & -0.224 & 0.091 & 0.130 & -0.082 & 0.017 & -0.046 \\
\hline \multicolumn{8}{|c|}{ Satisfaction with Physical health } \\
\hline Pearson Correlation & $-0.488^{* *}$ & $-0.359 *$ & -0.148 & -0.190 & -0.162 & -0.254 & -0.342 \\
\hline p-value & $0.006^{* *}$ & $0.051^{*}$ & 0.436 & 0.315 & 0.391 & 0.175 & 0.064 \\
\hline \multicolumn{8}{|c|}{ Satisfaction with Psychological health } \\
\hline Pearson Correlation & $-0.392^{*}$ & -0.331 & -0.102 & -0.185 & 0.032 & -0.163 & -0.245 \\
\hline p-value & $0.032^{*}$ & 0.074 & 0.592 & 0.329 & 0.865 & 0.391 & 0.193 \\
\hline \multicolumn{8}{|l|}{ Social relationships } \\
\hline Pearson Correlation & -0.086 & -0.018 & -0.049 & 0.120 & 0.144 & -0.320 & -0.045 \\
\hline \multicolumn{8}{|c|}{ Satisfaction with environment } \\
\hline Pearson Correlation & $-0.251^{* *}$ & -0.293 & -0.310 & $-0.071^{* *}$ & -0.145 & $-0.217^{* *}$ & $-0.291^{* * *}$ \\
\hline p-value & $0.001^{* *}$ & 0.093 & 0.096 & $0.003^{* *}$ & 0.068 & $0.001^{* *}$ & $0.000^{* *}$ \\
\hline
\end{tabular}

wives of patients with AUD and OUD is very low [12-15]. QoL was found to be lowest in the domain four of WHO QoL Bref (satisfaction with environment). This domain measures QoL in terms of satisfaction with safety, finances, leisure activities and access to health-care services. The safety of women may be compromised due to high levels of domestic violence at the hands of persons with SUD [16]. The present study also found high financial burden and burden on disruption of leisure activities, which could have led to low QoL on domain four. The partner of a person with SUD may have interference in their tasks, interpersonal relations, social relations, poor mental and physical health, social isolation, and poor family conditions [1]. All these factors in combination negatively impact the QoL of spouses of patients with AUD and OUD.

Our study shows that increasing discrimination stigma had a significant negative impact on QoL with respect to satisfaction with environment. Although, the impact of family-stigma on QoL of wives has not been studied in India, two studies from elsewhere have reported that family stigma reduced QoL among caregivers and anticipated stigma had direct negative impact on psychological and physical health of caregivers of Substance dependent patients $[5,6]$. Wives of patients with substance sue disorders suffer stigma in the form of blame, shame and contamination. They are often blamed for the initiation and continuation of substance use among their husbands and suffer shame because of the same. This leads to a significant impact on their emotional health which can worsen QoL [4].

Higher burden of caregiving (mainly financial burden) was significantly negatively correlated with QoL, which is supported by previous study [7]. Financial burden is due to money spent on substance use, loss of productivity, expenses related to treatment of SUD, debts, etc. Over the course of illness, SUD negatively impacts the physical health, psychological health, marital relations, and lead to psychiatric morbidity among wives. All these factors may lead to significant reductions in QoL.

Although the study was conducted using stringent methodology and standardized scales in local language, a few limitations should be noted while interpreting the results. Small sample size, cross sectional nature, inclusion of wives of only in-patients and patients with severe SUD were the major limitations of the study. All the variables including QoL, stigma, and burden are dynamic in nature and affected by multiple variables, some of which might have been missed, thus limiting the results further.

\section{CONCLUSION}

Wives of patients with SUD face significant burden and stigma which reduces their QoL significantly. Thus, management wives along with 
the patients of SUD should also be part of de-addiction treatment protocol.

\section{AUTHORS' CONTRIBUTIONS}

All the authors have made considerable contributions in the research work and formulation of the manuscript.

\section{CONFLICTS OF INTERESTS}

The authors confirm that this article has no conflict of interests.

\section{AUTHORS FUNDING}

No funding was received for the research.

\section{REFERENCES}

1. Birkeland B, Foster K, Selbekk AS, Høie MM, Ruud T, Weimand B. The quality of life when a partner has substance use problems: A scoping review. Health Qual Life Outcomes 2018;16:1-14.

2. Malik P, Kumar N, Sidhu BS, Sharma KC, Gulia AD. Impact of substance dependence on primary caretaker in Rural Punjab. Delhi Psychiatry J 2012;15:72-8

3. Kaur A, Mahajan S, Deepti SS, Singh T. Assessment of role of burden in caregivers of substance abusers: A study done at Swami Vivekananda drug de-addiction centre, Govt. Medical college, Amritsar. Int J Community Med Public Health 2018;5:2380.

4. Arun P, Garg R. Stigma of mental illness. In: Chadda RK, Kumar V, Sarkar S, editors. Social Psychiatry: Principles and Clinical Perspectives. New Delhi: Jaypee Publishers; 2018. p. 409-25.

5. Luoma JB, Twohig MP, Waltz T, Hayes SC, Roget N, Padilla M, et al. An investigation of stigma in individuals receiving treatment for substance abuse. Addict Behav 2007:32:1331-46.

6. Marshall O. Associative Stigma among Families of Alcohol and other Drug Users. [Honors Theses]. Joondalup, Australia: Edith Cowan University; 2013. Available from: https://ro.ecu.edu.au/theses hons/104 [Last accessed on 2021 Jan 25].

7. Cicek E, Demirel B, Ozturk HI, Kayhan F, Cicek IE, Eren I. Burden of care and quality of life in relatives of opioid dependent male subjects. Psychiatr Danub 2015;27:273-7.

8. Saxena S, Chandiramani K, Bhargava R. WHOQoL Hindi: A questionnaire for assessing quality of life in health care settings in India. World Health Organization quality of life. Natl Med J India 1998;11:160-5.

9. Garg R, Arun P, Chavan BS. Reliability of the stigma scale in the Indian setting. Indian J Soc Res 2013;54:267-75.

10. Pai S, Kapur RL. The burden on the family of a psychiatric patient: Development of an interview schedule. Br J Psychiatry 1981;138:332-5

11. Sathvik BS, Parthasarathi G, Narahari MG, Gurudev KC. An assessment of the quality of life in hemodialysis patients using the WHOQOL-BREF questionnaire. Indian J Nephrol 2008;18:141-9.

12. Marcon SR, Rubira EA, Espinosa MM, Belasco A, Barbosa DA. Quality of Life and stress in caregivers of drug-addicted people. Acta Paul Enferm 2012;25:7-12.

13. Aragao AT, Milagres E, Figlie NB. Quality of life and hopelesness of relatives of addicted. Psico-USF 2009;14:117-23.

14. Santos EC, Martin D. Caregivers of alcohol addicted patients in the city of Santos, SP, Brazil. Rev Bras Enferm Bras 2009;62:194-9.

15. Soni R, Upadhyay R, Meena PS, Jain M. Psychiatric morbidity, quality of life and marital satisfaction among spouse of men with opioid dependence syndrome: A study from North India. Int J Adv Med 2017;4:556-61

16. Sarkar S, Patra B, Kattimani S. Substance use disorder and the family: An Indian perspective. Med J Dr DY Patil Univ 2016;9:7-14 